\title{
Analysis on the Spatial and Temporal Differences of AEE and Its Potential Improvement in China Based on Strong Disposability
}

Dong-Mei SHI ( $\square$ shidongmeide@126.com)

Hebei GEO University, Shijiazhuang, China

\section{Research Article}

Keywords: Agricultural carbon emissions, agricultural ecological efficiency, strong disposability, temporal and spatial differences, intensive use potential

Posted Date: January 26th, 2022

DOl: https://doi.org/10.21203/rs.3.rs-1298231/v1

License: (9) (i) This work is licensed under a Creative Commons Attribution 4.0 International License. Read Full License 


\section{Abstract}

Agricultural eco-efficiency (AEE) emphasizes the unification of agriculture production efficiency and environmental benefits. It is an important indicator to measure agriculture's high-quality and sustainable development. Therefore, improving agricultural ecological efficiency is the key to achieving high-quality and sustainable agricultural development. The work uses the EBM-Super-ML method with strong disposability of undesired output to calculate the AEE and further in-depth the spatial-temporal differences driving factors and promotion potential of AEE. The result shows that the overall average value of China's AEE is increasing and has substantial regional heterogeneity. From the analysis of the improvement potential of agricultural ecological efficiency, the mean value of output inefficiency is 0.05 , and input inefficiency is 0.07 . Among the undesired output, the emission reduction ratio of the agricultural film can reach up to $40 \%$. Among the input elements, the potential for intensive use of labor input is the largest, the average value in the eastern region is relatively high. The input intensity coefficient of agricultural machinery is negative, so the utilization rate of machinery and equipment should be increased. Based on this, the paper put forward some policy recommendations to improve agriculture's high-quality, sustainable development and the AEE.

\section{Preface}

China's agricultural economy has developed rapidly Since the reform and opening up in 1978. The total output of grain, meat, and aquatic products accounted for about $20 \%, 25 \%$, and $33 \%$ of the corresponding supply in the world in $2017^{[1]}$, but the application amount of chemical fertilizer, mulching films, and pesticide respectively increased by 6.6 times, 5.3 times and 2.3 times $^{[1]}$. This agricultural production mode which depends on the high inputs of production factors, has led to increased agricultural non-point severe source pollution. According to the soil pollution survey bulletin in 2014 , the total exceeding the rate of soil pollution points is as high as $16.1 \%^{[2]}$. For this reason, the government has paid more attention to the development of ecological agriculture ${ }^{[1]}$ and issued a series of policies ${ }^{[3]}$, which provides strong support for the healthy and sustainable development of national economy and Society ${ }^{[1]}$. However, the utilization rate of agricultural resources in China is relatively low. Such as, in 2018 , the utilization rates of chemical fertilizer and pesticide were respectively $37.8 \%$ and $38.8 \%[4]$, the comprehensive utilization rate of livestock and poultry manure was about $60 \%$, the recovery rate of agricultural film is less than $2 / 3$.

China's agricultural growth mainly depends on the intensive input of production factors. Therefore, many research studies have quantified the performance of AEE. The research mainly used some methods, such as the ratio method, life cycle assessment (LCA), ecological footprint method, stochastic frontier analysis $(\mathrm{SFA})$, and data envelopment analysis (DEA) ${ }^{[6]}$. The research areas mainly include agricultural resource allocation efficiency, agricultural joint production efficiency, evolution characteristics of efficiency ${ }^{[7]}$, temporal and spatial differences, etc.

The analysis results include the following aspects. China's agricultural eco-efficiency value is generally low. Due to differences in economic development levels and resource endowments, the AEE apparent regional differences and spatial agglomerations. The distribution is high-high aggregation and low-low accumulation, higher in the east and west area and lower in the central ${ }^{[8]}$. The main reasons for the low efficiency of AEE are excessive, such as agricultural machinery, land sown area, and agricultural carbon emissions ${ }^{[9]}$. DEA relaxation usually analysis AEE Improvement, which provides an essential reference for the synergistic improvement of regional AEE. So, we should pay attention to improving the management level enhancing resource allocation of agricultural production.

In conclusion, the existing literature mainly focuses on measuring and analyzing the spatial-temporal evolution characteristics of AEE (agricultural ecoefficiency). It rarely explores the causes of AEE loss by combining the slack of agricultural input factor and output insufficiency ${ }^{[10]}$. So we use the Strong Disposability-EBM-Super Efficiency-Undesirable-Malmquist Productivity Index to estimate the AEE and its improvement potential in China. The main research contents are as follows.

Section1. Construct the theoretical analysis framework of AEE. The work integrates resource-environment-economy into the same analytical framework, hoping to provide a reference for decision-making to achieve sustainable agricultural development and high-quality development goals.

Section2. Comprehensively calculates the agricultural AEE from a combination of static and dynamic. Analyze the evolution law of AEE and identify the primary sources of patio-temporal differentiation of AEE in China.

Section3. Analyze the inefficiency of agricultural ecology and identify growth potential. Exploit the possibility of improving China's AEE from regional, interprovincial, and elemental levels to provide scientific decision-making basis for improving the quality of China's agricultural green development.

Section4. The article summarizes and discusses the research content and analyzes future research.

The contribution of this paper lies in two aspects. The first is to study the temporal and spatial differences of AEE and its improvement targets from the perspective of disposability and establish a scientific and reasonable model of AEE. The second is to explore the potential of improving China's AEE based on input and output and analyze the direction of improvement. It has important theoretical and practical significance for implementing the rural revitalization strategy in Chinese, promoting high-quality agricultural development and sustainable agricultural development.

\section{The Aee Calculation Results}

\section{The AEE calculation results}

The paper makes a detailed analysis of China's agricultural ecological efficiency calculation results from two aspects: time and space. The temporal trend is analyzed from the overall mean and kernel density distribution. The spatial distribution trend is analyzed from the regional mean and cluster distribution. 
Timing characteristics of AEE. As shown in Fig. 1, the mean value of AEE (MI, EC, TC, SE) is more significant than one during the period from 2010 to 2018 , and the overall growth is in a state of development. Among them, the fluctuations in 2010-2015 are relatively small and relatively large in 2016-2018. The fluctuation range of EC is relatively tiny, and the SE average fluctuates wildly. The average value of MI is affected by TC and declines from 2017 to 2018.

The AEE kernel density distribution. As shown in Fig. 2, in the representative years from 2010 to 2018, the MI, EC, SE position of the wave peak is unchanged, and in some years have small wave peak, it appears high-high and low-low agglomeration phenomenon. The peak position of the TC wave is unstable, and the low-low aggregation is more evident in 2016 and 2018. From the kurtosis point of view, the AEE was relatively concentrated in 2010 , and inefficient units and ultra-efficient units accounted for a relatively low. The peak value in 2016 was the smallest, and there are multiple peaks, indicating that the efficiency value has multiple convergence points. Numerical values are relatively scattered; there is no significant change in the width of kurtosis during the study period, indicating that the differences between provinces have not changed significantly (Xiang, Wang et al. 2020).

The AEE spatial distribution. We analyze the spatial pattern of China AEE in mean scale and agglomeration distribution aspects ${ }^{[11]}$.

Spatial mean distribution. The mean value of efficiency can reflect the overall trend of the sample ${ }^{[12]}$, and different regions have different characteristics ${ }^{[12]}$. As shown in Fig. 3, the various efficiency values in the eastern part are relatively high, and the average values of the ecological efficiencies MI, TC, and SE in each region are all greater than 1 . Only the average EC in the western area is less than 1.

Spatial agglomeration distribution. According to the fluctuation range of the efficiency value, divided China's agricultural total factor productivity into four types: rapid growth (<1.2), increase (1 1.2), decrease (0.8 1), and rapid decline (>0.8). As shown in Fig. 4, the trend of high-high aggregation and low-low aggregation of efficiency values is relatively apparent, and the efficient development of different regions is different. In 2018, the provinces with lower MI in the western region saw rapid growth in SE and TC, EC is falling rapidly, and in-depth analysis is needed. The eastern region is economically developed, and the MI of most provinces are in a state of growth, but the SE and TC values are low; the scale efficiency SE in the central region is better, and the TC is in a state of decreasing. From the average point of view, the provinces in the high-efficiency group are located in the eastern and western region, while some provinces in the northeast, west, and central regions are mainly in the middle and low-efficiency group, which is consistent with the conclusions of Fang ${ }^{[7]}$.

\section{The Improvement Potential Of Aee}

While improving economic benefits, modern agricultural production destroys the agricultural ecological environment and efficiency. It is mainly reflected in the redundant input of agricultural production factors and insufficient agricultural output. The degree of China's agricultural ecological inefficiency is the potential improvement of agricultural ecological efficiency. The higher the degree of inefficiency, the greater the improvement potential. The improvement approach includes two aspects. One is to achieve the maximum agricultural output under the premise of given factor input and ecological environment impact ${ }^{[4]}$, possible a few agricultural production factors to achieve a given output.

The overall inefficiency of AEE. The paper uses the slack measure of input-output sub-indices to decompose agroecological inefficiencies in each region. According to the decomposition results, from 2009 to 2018, the overall ratio of agroecological inefficiency was 0.7333 . The average agricultural input factor inefficiency value was 0.0723 , and the average output inefficiency was 0.0515 . In comparison, the proportion of input factors was unbalanced. It is the main reason for China's agricultural ecological efficiency decline. The inefficiency value of input factors fluctuates wildly, reaching the maximum inefficiency value of 0.3257 in 2016 . The inefficiency value of output factors fluctuates little. It is generally in a downward situation, which reflects that China attaches importance to the high-quality development of the agricultural industry and the protection of AEE in recent years.

The region inefficiency of AEE. The areas of AEE in China are located in western regions such as Xinjiang, Gansu, Shanxi, Heilongjiang, and Jilin. The provinces with low average efficiency include Gansu (0.7569), Shanxi (0.8944), Jilin (0.9620), and Heilongjiang (0.9932). As Fig. 7 shown, Beijing, Hebei, Jiangsu, Qinghai, Shanghai, Yunnan, and Zhejiang have relatively high levels of inefficiency in input factors. Beijing, Shanxi, and Hebei have fairly significant input inefficiencies, and Beijing, Shandong, and Shanxi output inefficiency values are high.

\section{Driving Factor Of Aee}

Further analysis of the input and output factors shows excellent redundancy in the total power of agricultural machinery, land, labor, intermediate consumption input, unexpected output, and total output value. The allocation structure of various factors is unreasonable, potentially saving.

Intensive utilization potential of input factors. From 2009 to 2018, the average intensive utilization potential of the labor force, land, intermediate consumption, and total mechanical power in the primary industry was $3.89 \%, 1.18 \%, 0.54 \%$, and $0.36 \%$. It indicates that the potential of intensive utilization of the labor force in agricultural production is significant, with the redundancy ratio exceeding $20 \%$ in 2016 . The second is the land, with the redundancy ratio exceeding $30 \%$ in 2016. It is necessary to reduce land input or improve the intensive use of other input factors to improve the land output rate ${ }^{[13]}$.

In the mean values of all provinces, Gansu, Jilin, and Shanxi have insufficient inputs, so it is necessary to adjust the input ratio of factors to improve the output efficiency of land. The input factors in Beijing, Hebei, Zhejiang, and Yunnan are too high, especially the labor input, which exceeds 50\% in Beijing, Hebei, and Zhejiang.

Adjustment proportion of expected output. From 2009 to 2018, taking into account carbon emissions and non-point source pollution of petrochemical supplies, the mean value of the target output value changed slightly, basically rising first and then falling. In 2018 , it was somewhat higher than that in 2009 , with a growth rate of $8.31 \%$. The average real output value showed a yearly rise, with a growth rate of $91.71 \%$. As shown in the figure, the slack of real output value keeps increasing, and the actual value of output is much higher than the projection value, with the adjustment range rising from $45.2-158.89 \%$. It is 
necessary to adjust the input proportion of production factors appropriately, improve the quality of agricultural products ${ }^{[14]}$, and transition from quantity growth to quality improvement.

From the analysis of the average value of each province in China, the intensive use difference of output value is more significant among the 30 regions under the carbon constraint from 2009 to 2018. The output projection value is higher in Henan and Shandong. The slack value is higher in Jiangxi and Shanghai. The improvement ratio is most significant in Zhejiang, followed by Shaanxi and Jiangsu, with the improvement ratio exceeding $200 \%$. Input-output ratios should be further analyzed in these areas to achieve optimal ecological efficiency. Jilin, Shanghai, and Shanxi have an improvement ratio below $10 \%$. Only Gansu has a low average output value and needs to increase the total agricultural output value.

Emission reduction pressure of unexpected output. Unexpected output indicators include carbon emissions and non-point source pollution of petrochemical products.

Total carbon emissions. During the research period of the DMU, the average value of national total carbon emissions from 2009 to 2018 generally increased first and then decreased, which has a great relationship with the country paying more attention to environmental factors this year. All regions pay more attention to agricultural ecological production and green development ${ }^{[15]}$. From the perspective of time, China has shown a trend of continuous emission reduction. In 2015 and 2018, the emission value was less than the target value and achieved carbon balance. The mean values of most regions in the sample analysis period align with the requirements. Gansu has the highest carbon emission reduction pressure, followed by Jilin, Heilongjiang, and Xinjiang. Economically developed areas such as Shanghai, Jiangsu, Tianjin, and Beijing pay more attention to the green and sustainable development of agricultural production, and their carbon emissions are relatively good.

Non-point source pollution. The pressure of emission reduction for agricultural film residues is high, and significant emissions are required to reduce for the rest of the period except 2018. The stress of reducing pesticide residues is low. The sample analysis period is less than the target value, related to the national attaching great importance to pesticide residues and ensuring food safety. The loss of chemical fertilizer is relatively sound, the pressure of reducing emission is relatively tiny. Agricultural film residues and pesticide residues are under pressure to reduce emissions in Gansu Province. Heilongjiang pressure to reduce emissions of agricultural film residues and chemical fertilizer loss. Jilin and Xinjiang need to reduce non-point source pollution indicators. Shanxi agricultural film residues. There is tremendous pressure to reduce emissions of residues and fertilizer loss.

\section{Discuss}

The paper considers the constraints of non-expected output indicators such as carbon emissions and the strong disposability of agricultural non-expected output. Under these conditions, we constructed a super-efficiency-ML index model for panel data of agricultural production inputs and output factors in 30 regions of China from 2009 to 2018 . The work analyzed the model results from three aspects: the change of ecological efficiency, its driving characteristics, and its potential for improvement.

Firstly. The work analyzed the overall trend and temporal-spatial differences of agricultural eco-efficiency. The analysis results show that the overall average value of $A E E$ and decomposition efficiency in China increases ${ }^{[3]}$. Among them, the mean value of MI decreased slightly in the recent two years and was greatly affected by TC. The overall mean of EC was low, the SE is high and has maintained a slight growth in the recent two years. The nuclear density distribution shows that the distribution of Ml efficiency values is relatively concentrated; the peak heights of EC values vary significantly in different periods, with high and high aggregation and low and low aggregation phenomena ${ }^{[16]}$. The SE efficiency value fluctuates wildly, with a significant decrease and multiple small-scale agglomerations in 2016. The peak heights of TC values vary greatly, among which the peak in 2016 was the lowest with small peaks and tailings. The economy and technology in the eastern region are relatively developed, and the average AEE efficiency is higher. The MI and SE efficiency values are significantly higher than those in the central and western regions. The average TC efficiency in the west area showed a regression state, and it showed a rapid decrease in 2018.

Second. We analyze the improvement potential of AEE in China. Under carbon constraints, the proportion of agroecological inefficiency units in China is 0.07 , showing an expanding trend, and the inefficiency mainly originates in the western region. The average output inefficiency is 0.0515 , and seven areas have an average value exceeding 0.05 . we should appropriately reduce expected output and the redundancy in undesired production. The average weight of input inefficiency is 0.0723 and fluctuates wildly, and there are nine regions with an average value exceeding 0.05 . We should adjust the input structure of agricultural production to improve agricultural ecological efficiency.

Thirdly. The work analyzes the driving factors of AEE. Among the input factors, the labor force has the most significant potential for intensive utilization, followed by the input of land factors. The high average value of input factors is mainly due to the eastern region, while the western part is insufficient. The agricultural machinery input represents modern agriculture, is not conducive to improving agricultural ecological efficiency to a certain extent. The actual value of expected output is much higher than the target value, and the degree of slack increases year by year. In the undesired output, the reduced pressure of agricultural film is the greatest and should be strengthened recycling and treatment of the agricultural film. The average value of carbon emissions in economically developed regions meets the requirements within the sample analysis period. The actual value of carbon emissions in Zhejiang and Shanghai is less than the target value and achieved a significant balance of agricultural carbon has been.

Improving China's agricultural economic benefits has mainly relied on many agricultural input production factors for a long time. This extensive farming method is not conducive to enhancing agricultural ecological efficiency. It is necessary to adjust the input structure of agricultural production factors, reduce undesired agricultural output, and improve agricultural productivity-the sustained level of development. At the same time, we should also pay attention to the balanced development between regions. The economically developed eastern region has a high degree of agricultural mechanization, but it is not conducive to improving agricultural ecological efficiency. Improve the use efficiency of agricultural machinery. The large-scale use of agricultural film in the western regions

Page $4 / 13$ 
with weak economic development is the main reason for the undesired output. It is necessary to improve agricultural film products' scientific and technological innovation and the speed of achievement promotion. The inefficiency of labor and land indicators shows that agriculture is still extensive management in most areas. Economically developed regions pay more attention to ecological agriculture development within the selected indicators and research scope. The carbon emission index is more reasonable, and the financially underdeveloped areas have more significant pressure on carbon emission reduction.

The insufficient of paper. Although the work systematically analyzes the spatiotemporal distribution characteristics of China's AEE and the intensive utilization of elements, the research on the interaction between the indicators is insufficient due to space limitations. We should be carried out follow-up research indepth analysis from two aspects. First, optimize the AEE calculation model and the corresponding indicator settings, and analyze the development of AEE according to different situations and regional systems. The second is to build a spatial data model, conduct an in-depth analysis of the influencing factors of $\mathrm{AEE}$, and further analyze the direct and indirect effects of the corresponding indicators to provide a theoretical reference for improving China's agricultural ecological efficiency.

\section{Policy Recommendations}

Based on the above conclusions, put forward the following policy recommendations.

On the one hand, construct a comprehensive evaluation system of AEE. From the perspective of the production function, the paper selects the macro data of labor, land, capital, technology, etc., as input indicators and constructs an ecological efficiency measurement model[4], which reflects the overall situation of the country. According to the characteristics of different industries to establish a comprehensive and systematic accounting system of agricultural ecological efficiency ${ }^{[17]}$, and to select scientific and reasonable variables for calculation and provide more real help of input proportion, which is more conducive to protecting the agroecological environment.

The second is to establish an information platform of big agricultural data. The representativeness and accuracy of the data are prerequisites for the usability of the model results. It establishes an open digital information system ${ }^{[18]}$ and provides agroecological technologies and information to departments, management organizations, and farmers. It not only prevents agricultural, environmental pollution but also improves farmers' awareness of environmental protection $^{[19]}$. It also collects the production information of these subjects, ensuring the comprehensiveness and accuracy of the data.

The third is to promote environment-friendly agricultural technology innovation. Agricultural management organization is a link of small farmers to the big market. Construction agricultural management organizations can adjust the input ratio of agricultural production factors and reduce undesired outputs, such as carbon emissions and non-point source pollution, through the standardization of production ${ }^{[20]}$. Active foster agricultural business entities represented such as family farms and farmer cooperatives ${ }^{[21]}$ can effectively drive green, organic, technological. Other elements in agricultural development ${ }^{[22]}$ promote the development of rural industries and increase farmers' income.

The fourth is to Promote environmentally friendly agricultural technology innovation. Agricultural technological innovation and the development of the agricultural service industry are important ways to improve agricultural ecological efficiency and achieve sustainable agricultural development and economic growth. We should strengthen Environmentally friendly agricultural technology innovation with low input, green, and sustainability. Such as applying bioorganic fertilizer or planting green manure instead of chemical fertilizer, promoting the planting and production of bio-pesticides and organic agricultural products. Promot scientific fertilization technology to improve the utilization rate of chemical fertilizers and use degradable agricultural film and pesticide packaging to enhance the recycling of agricultural wastes utilization to enhance soil conservation behavior in farmland ${ }^{[23]}$.

At last, Scientifically measure the input of production factors. Agricultural non-point source pollution and carbon emissions are undesired outputs in the agricultural production process. The increase of land management scale and production means has become increasingly severe ${ }^{[24]}$, reducing agricultural ecological efficiency. Therefore, scientifically measuring the input ratio of production factors can reduce non-point source pollution and carbon emissions in the agricultural production process. At the same time, we should give full play to the spatial spillover effect of high-efficiency areas and improve the utilization rate of factors. In areas with high production potential, support for scale operations should be considered ${ }^{[25]}$ to improve the overall level of agroecological efficiency ${ }^{[26]}$.

\section{Method}

Agricultural eco-efficiency is the ratio of the economic value added by agricultural production to the consequences of environmental impact ${ }^{[27]}$. DEA method has become the most commonly used method for AEE evaluation ${ }^{[28]}$. The main reason is that the DEA method ignores the influence of random errors and can overcome the impact of non-technical factors on the frontier production function ${ }^{[18]}$. It has advantages, including simultaneous processing of multiple inputoutput elements and nonparametric processing of effective boundary. Obtaining the current output level at a lower input level is more conducive to achieving the goal of sustainable agricultural development ${ }^{[29]}$. By controlling the state of economies of scale, orientation, disposability of elements, and production frontier functions, the work uses the SUPER-ML index to measure the AEE of various regions in China and further analysis of the temporal and spatial differences in decomposition efficiency, the slackness of input-output indicators, and inefficiency.

ML index

Malmquist index usually to analyzes the panel data of observed values at multiple time points. Färe first used the DEA method to calculate the Malmquist index(MI) and further decomposed it into technical efficiency change (EC) and technical change (TC), which commonly used to analyze productivity changes, 
and the effect of technological efficiency and technological progress on productivity change. Chung introduced the directional distance function into the Malmquist index to deal with the problem of unexpected output, which is called the Malmquist-Luenberger (ML)index ${ }^{[30]}$. The core is to solve the problem of unexpected output. The Fixed Malmquist index takes the single-phase front of a fixed period as the reference front for calculating MI ( $\mathrm{t}-1, \mathrm{t})$ in each period [31]. The $\mathrm{Ml}$ and its decomposition efficiency model are as follows:

$$
\begin{aligned}
M I(t-1, t) & =\frac{S c o r e_{-} f\left(x_{-} t, y_{-} t\right)}{S c o r e_{-} f\left(x_{-} t-1, y_{-} t-1\right)} \\
E C(t-1, t) & =\frac{S c o r e_{-} f\left(x_{-} t, y_{-} t\right)}{S c o r e_{-} f\left(x_{-} t-1, y_{-} t-1\right)}
\end{aligned}
$$

$T C(t-1, t)=\frac{M I(t-1, t)}{E C(t-1, t)}=\frac{\left(\frac{\text { Score }_{-} f\left(x_{-} t, y_{-} t\right)}{\text { Score }_{-} f\left(x_{-} t-1, y_{-} t-1\right)}\right)}{\left(\frac{\text { Score }_{-} f\left(x_{-} t, y_{-} t\right)}{\text { Score }_{-} t-1\left(x_{-} t-1, y_{-} t-1\right)}\right)}$

$$
=\frac{\left(\frac{S c o r e_{-} f\left(x_{-} t, y_{-} t\right)}{S c o r e_{-} t\left(x_{-} t, y_{-} t\right)}\right)}{\left(\frac{\text { Score }_{-} f\left(x_{-} t-1, y_{-} t-1\right)}{\text { Score }_{t}-1\left(x_{-} t-1, y_{-} t-1\right)}\right)}
$$

Where: Score_f $\left(x_{-} t, y_{-} t\right)$ represents the DEA efficiency value obtained from the reference fixed front. Among them, $\frac{S c o r e_{-} f\left(x_{-} t, y_{-} t\right)}{S c o r e} t(x-y)$ reflects the distance between the front of phase $t$ of the fixed front; $\frac{S c o r e_{-} f\left(x_{-} t-1, y_{-} t-1\right)}{S c o r e_{-} t-1\left(x_{-} t-1, y_{-} t-1\right)}$ reflects the distance between the front of phase $t-1$ of the fixed front. The ratio of the two reflects the change of the t-period front compared with the $\mathrm{t}-1$ period front.

Strong Disposability-Undesirable-EBM-Super Efficiency model

Tone and Tsutsui proposed the EBM (Epsilon-Based Measure) model. It is a hybrid model that includes two types of distance functions: radial and SBM. The non-point source pollution and carbon emission in agricultural production as unexpected output. The projection direction of the evaluated DMU in the model is to increase good output and reduce bad output (unexpected output). Referring to the setting of the model by Wang, select the Super Efficiency-EBM model with four inputs, one expected output, and four unexpected outputs. In the planning formula, Max represents the strong, effective frontier. Record 30 provinces as decision-making units $(\mathrm{DMU})$ as $\mathrm{x}_{\mathrm{i} j}$, in period $\mathrm{t}(\mathrm{t}=1, \ldots, \mathrm{T})$, there are $\mathrm{k}(\mathrm{k}=1, \ldots, 30) \mathrm{DMU}$, each decision making unit has $\mathrm{m}$ input $\mathrm{X}=\left(\mathrm{x}_{1}, \mathrm{x}_{2}, \cdots, \mathrm{x}_{\mathrm{m}}\right) \in \mathrm{R}_{+}^{\mathrm{m}}, \mathrm{n}$ expected output $Y_{r}=(r=1,2, \ldots, n) \in R_{+}^{n}$ and $J$ non-expected output $Y_{j}=(j=1, \ldots, j) \in R_{+}^{j}, X=\left\{X_{i j}\right\} \in R^{M \times N}, Y=\left\{Y_{i j}\right\} \in R^{M^{*} N}$, and $X>0, Y>0$ respectively are input and output matrices (Yin, Zhu, 2020). The model is as follows:

$$
\rho^{*}=\max \frac{\theta-\epsilon_{x} \sum_{i=1}^{4} \frac{W_{i}^{-} S_{i}^{-}}{x_{i k}}}{\phi+\epsilon_{y} \sum_{r=1} \frac{W_{r}^{+} S_{r}^{+}}{y_{r k}}+\epsilon_{b} \sum_{p=1}^{j} \frac{W_{p}^{b_{-}-S_{p}^{-}}}{b_{p k}}}
$$

s.t. $\sum_{j=1, j \neq j o}^{k} X_{i j} \lambda_{j}+S_{i}^{-}=\theta X_{i k^{\prime}}, i=1,2,3,4 \sum_{j=1, j \neq j o}^{k} y_{r j} \lambda_{j}-S_{r}^{+}=\phi y_{r k}, r=1$

$\sum_{p=1}^{2} b_{p j} \lambda_{j}+S_{p}^{b_{-}}=\phi b_{p k^{\prime}} p=1,2,3,4 \lambda_{j} \geq 0, S_{i}^{-}, S_{r}^{+}, S_{p}^{b_{-}} \geq 0$

Where: $\rho^{\star}$ is the best efficiency under the condition of constant return to scale. $\theta$ is the planning parameter of the radial part. $\epsilon_{X^{\prime}} \epsilon_{y}$ is key parameter. Satisfy 0 $\leq \epsilon_{X^{\prime}} \epsilon_{y} \leq 1 . W_{i}^{-}$is the importance of input indicators, it meets $\sum_{i=1}^{4} W_{i}^{-}=1 ; x_{i k}$ and $y_{r k}$ are the $\mathrm{i}$ inputs and the r outputs of decision-making of DMU $\mathrm{k}_{\mathrm{k}}$ $S_{i}^{-}$is the relaxation of input element i. $\phi$ is the output expansion ratio. $S_{r}^{+}$is the relaxation variable of the expected output of class r. $S_{p}^{b}-$ is the relaxation variable of p-type unexpected output. $W_{r}^{+}, W_{p}^{b}$-is the weight of both index. $b_{p k}$ is the p unexpected output of $\mathrm{DMU}_{\mathrm{k}}$, $\mathrm{q}$ is the number of unexpected outputs, $\mathrm{j}$ is the $\mathrm{DMU}, \lambda_{j}$ is the linear of combination coefficient. $j_{0}$ represents the super efficiency value of $\mathrm{DM} U_{j}$ on the new effective frontier excluding $\mathrm{DM} U_{j o}$ when the commented decision unit is $\mathrm{DM} U_{j o}$.

Efficiency decomposition

According to the idea of ecological efficiency measurement, we carried out further research and decomposed the calculation formula of the ineffective rate of each input-output element. The projection value is the projection of the evaluated DMU on the leading edge. The relative gap between the current value and the projection value represents the inefficiency of each input and output of the DMU. The improvement value of inefficient DMU includes two parts: the one is proportional movement, and the other is slack movement. Combined with Cooper's decomposition idea, the efficiency decomposition formula and inefficiency decomposition formula of input-output elements are as follows: 


$$
\begin{gathered}
e_{i}=\frac{x_{i k}^{T}-s_{i}^{-}}{x_{i k}^{T}}, e_{r}=\frac{y_{r k}^{g, T}}{y_{r k}^{g, T}+s_{r}^{+}}, e_{q}=\frac{y_{q k}^{b, T}-s_{q}^{-}}{y_{q k}^{b, T}} \\
i e_{i}=\frac{1}{2 m} \frac{s_{i}^{-}}{X_{i k}^{T}}, i e_{r}=\frac{1}{2\left(s_{1}+s_{2}\right)} \frac{s_{r}^{+}}{y_{i k}^{g, T}}, i e_{q}=\frac{1}{2\left(s_{1}+s_{2}\right)} \frac{s_{q}^{-}}{y_{q k}^{b, T}}
\end{gathered}
$$

Where: $s_{i}^{-}, s_{r}^{+}, s_{q}^{-}$expression relaxation variables of input, expected output, and unexpected output. $\mathrm{e}_{\mathrm{i}}, \mathrm{e}_{\mathrm{r}}$, $\mathrm{e}_{\mathrm{q}}$ represent the efficiency decomposition formula of input factors, expected output, and unexpected output. $\mathrm{ie}_{\mathrm{i}}, \mathrm{i}_{\mathrm{r}}, \mathrm{ie}_{\mathrm{q}}$ represent the inefficiency decomposition formula. The efficiency decomposition formula obtains the efficiency level of each element, and the inefficiency decomposition formula obtains the decomposition of the total inefficiency, reflecting the promotion potential of each element to agricultural ecological efficiency.

\section{Variables And Data}

Input and output indicators. The optimal agricultural production efficiency needs to consider both agricultural production increase and agricultural emission control $^{[26]}$. Most literature believes that the selection of output variables should include expected and unexpected output ${ }^{[32]}$. From the perspective of the C-D production function, input factors mainly include labor force, land, capital, and technology ${ }^{[25]}$. The agricultural expected output consists of the gross output value of agriculture, forestry, animal husbandry, and fishery, which measures the economic benefits and overall results ${ }^{[33]}$. Unexpected agricultural production mainly comes from the excessive input or inefficient utilization of some production factors (Adu and Kumarasamy, 2018). The statistics of agricultural pollution mainly include COD and TN\&P emissions ${ }^{[34]}$. Therefore, as shown in Table 1. unexpected output in this paper comprises fertilizer residue, pesticide residue, agricultural film residue, and carbon emission of agricultural products (see Table 1).

Calculation of carbon emission. Agricultural greenhouse gases include $\mathrm{CH}_{4}$ and $\mathrm{N}_{2} \mathrm{O}$, which come from agricultural land, animal intestinal fermentation, and manure management ${ }^{[15]}$. According to the Unit Survey and Assessment method, agricultural carbon emissions mainly come from petrochemical products such as chemical fertilizers and pesticides, agricultural irrigation, tillage, agricultural machinery power, and methane emissions from animal husbandry and breeding production ${ }^{[35]}$. The work calculates agricultural carbon emissions from three aspects: input of agricultural materials ${ }^{[36]}$, carbon emissions from crop planting, and animal husbandry. The calculation formula is as follows:

$$
A C E=\sum_{i=1}^{n} E_{i} \times \delta_{i}=\sum_{i=1}^{n}\left(C+C H_{4 \text { crop }}+N_{2} O_{\text {crop }}+N_{1 i}+N_{2 i}\right)
$$

1

$$
C=\sum_{i=1}^{6} C_{i}=\sum_{i=1}^{6} X_{i} \cdot h_{i}
$$

2

$$
C H_{4 \text { crop }}=\sum_{i=1}^{n} S_{i} \times \alpha_{i}
$$

3

$$
N_{2} O_{\text {crop }}=\sum_{i=1}^{n} S_{i} \times \beta_{i}+P_{i} \times \gamma_{i}+Q_{i} \times \delta_{i}
$$

4

$$
N_{1 i}=\text { Days_alive }_{i} \times \frac{M_{i}}{365}
$$

5

$$
N_{2 i}=\square C_{i}+C_{i \square t-1 \square \square / 2}
$$

6

In formula (1), ACE is Total Hydrocarbon emission, $\mathrm{E}_{\mathrm{i}}$ is the consumption of class ith energy. $\delta_{\mathrm{i}}$ is carbon emission coefficient of class ith energy. According to IPCC's fourth assessment report (2007), carbon, methane, and nitrous oxide can replace with standard carbon dioxide. That is one ton of methane is equivalent to the greenhouse effect produced by 25 tons of carbon dioxide; one ton of nitrous oxide is equal to the greenhouse effect of 298 tons of carbon dioxide. 
In formula (2), $\mathrm{C}_{\mathrm{i}}$ is the carbon emission of agricultural supplies, $\mathrm{X}_{\mathrm{i}}$ is the amount of each carbon emission source, $\mathrm{h}_{\mathrm{i}}$ is the carbon emission coefficient of each carbon emission source. According to the agricultural supply's emission coefficient table, the total carbon emission can be obtained.

In formula $(3,4): \mathrm{CH}_{4 \mathrm{crop}}$ is the total annual methane emission of the planting industry. $\mathrm{S}_{\mathrm{i}}$ is the sowing area of crop, $\alpha_{i}$ is the methane emission coefficient per unit area of the crop. $\mathrm{N}_{2} \mathrm{O}_{\text {crop }}$ is the annual emission of nitrous oxide from the planting industry, $\beta_{\mathrm{i}}$ is the yearly emission background flux of nitrous oxide per unit area of the crop; $P_{i}$ is the annual total amount of nitrogen fertilizer applied to the crop, and $\gamma_{i}$ is the nitrous oxide emission coefficient of the crop; $\mathrm{Q}_{\mathrm{i}}$ is the total annual application amount of compound fertilizer for the crop, $\delta_{\mathrm{i}}$ is the nitrous oxide emission coefficient of compound fertilizer for the crop.

In formula (5,6), $\mathrm{N}_{1 \mathrm{i}}$ is the annual average feeding number of livestock with a slaughter rate greater than 1 , Days_alive $\mathrm{i}_{\mathrm{i}}$ is the average growth cycle of livestock, and $\mathrm{M}_{\mathrm{i}}$ is the annual slaughter amount of ith livestock. $\mathrm{N}_{2 \mathrm{i}}$ is the average yearly feeding amount of livestock with a slaughter rate less than 1 , and $C_{i} \square C_{i \square t-1 \square}$ is respectively represent the year-end stock of livestock.

Data sources. Referring to most kinds of literature, the original data of model indicators come from yearbooks, such as China Rural Statistical Yearbook, China Agricultural Economic Yearbook, and the annual statistical report of China's rural management, from 2009 to 2019. According to the availability and integrity of data, we chose generalized agriculture as the research object, including 30 provinces and autonomous regions of the Chinese mainland, and excluded incomplete data from Hongkong, Macao, Taiwan, Tibet. According to the provincial administrative region division method approved by the State Council in 2000, and divided the 30 local regions into East, Central, and West. The missing data of individual samples are processed by the interpolation method. It is adjusted to the constant price-output value in 2009 to eliminate inflation.

Descriptive statistics. As shown in Fig. 1, land area indicators are most concentrated, while pesticide residue indicators are scattered. To understand the relative difference of the indicators, measurement the standard deviation to reflect the fluctuation of the unit means. Among them, the coefficient of variation of the land area is the largest, which is 1.19 . It shows that the land input of the primary industry varies significantly between different provinces. The coefficient of variation of each indicator is relatively stable, around 0.8 , indicating differences within the other hands, but the fluctuations are similar.

\section{Declarations}

\section{Acknowledgment}

This work supports China National Social Science Foundation, Z20190082.

\section{Author contributions}

S.D.M. writing of the manuscript, funding acquisition, and project administration; L.C.X. participated in research design and editing; M.C.Y. translation, writing review, and editing. All of the authors have made corresponding contributions. We recognize them as co-authors and consider them as the first authors. All authors have read and agreed to the published version of the manuscript.

\section{Competing interests}

The authors declare no competing interests.

\section{References}

1. Liu, Y., L. Zou, and Y. Wang, Spatial-temporal characteristics and influencing factors of agricultural eco-efficiency in China in recent 40 years. Land Use Policy, 2020. 97.

2. Foley, J.A., et al., Solutions for a cultivated planet. Nature, 2011. 478(7369): p. 337-42.

3. Chen, X., C. Liu, and X. Yu, Urbanization, Economic Development, and Ecological Environment: Evidence from Provincial Panel Data in China. Sustainability, 2022. 14(3).

4. Xu, X.L., et al., The intellectual capital efficiency and corporate sustainable growth nexus: comparison from agriculture, tourism and renewable energy sector. Environment, Development and Sustainability, 2021. 23(11): p. 16038-16056.

5. Liu, Y., et al., Land consolidation engineering and modern agriculture: A case study from soil particles to agricultural systems. Journal of Geographical Sciences, 2018. 28(12): p. 1896-1906

6. Tenaye, A., Technical Efficiency of Smallholder Agriculture in Developing Countries: The Case of Ethiopia. Economies, 2020. 8(2).

7. Feng, C., et al., Green development performance and its influencing factors: A global perspective. Journal of Cleaner Production, 2017. 144: p. 323-333.

8. Barth, H., et al., Unpacking sustainable business models in the Swedish agricultural sector- the challenges of technological, social and organisational innovation. Journal of Cleaner Production, 2021. 304.

9. Liu, M., et al., The spatial aggregation of rural e-commerce in China: An empirical investigation into Taobao Villages. Journal of Rural Studies, 2020. 80 : p. $403-417$. 
10. Han, H., et al., Agricultural eco-efficiency loss under technology heterogeneity given regional differences in China. Journal of Cleaner Production, 2020. 250.

11. Martínez-Victoria, M., M. Maté-Sánchez-Val, and A.O. Lansink, Spatial dynamic analysis of productivity growth of agri-food companies. Agricultural Economics, 2019. 50(3): p. 315-327.

12. Zeng, L., X. Li, and J. Ruiz-Menjivar, The effect of crop diversity on agricultural eco-efficiency in China: A blessing or a curse? Journal of Cleaner Production, 2020. 276.

13. Jat, R.S., et al., Sustainability, productivity, profitability and soil health with conservation agriculture based sustainable intensification of oilseed brassica production system. Sci Rep, 2021. 11(1): p. 13366.

14. Esteves, R.C., A.L. do Amaral Vendramini, and F. Accioly, A qualitative meta-synthesis study of the convergence between organic crop regulations in the United States, Brazil, and Europe. Trends in Food Science \& Technology, 2021. 107: p. 343-357.

15. Souza Piao, R., et al., Green Growth and Agriculture in Brazil. Sustainability, 2021. 13(3).

16. Chen, Z., et al., Effects of joint adoption for multiple green production technologies on welfare-a survey of 650 kiwi growers in Shaanxi and Sichuan. International Journal of Climate Change Strategies and Management, 2021. 13(3): p. 229-249.

17. Demidova, S., et al., Development of Methodology and Assessment of Ecological Safety of the EAEU and CIS Regions in the Context of Sustainable Development. Economies, 2021. 9(3).

18. Zhong, F., et al., Eco-efficiency of oasis seed maize production in an arid region, Northwest China. Journal of Cleaner Production, 2020. 268.

19. Su, Y., et al., High probability of yield gain through conservation agriculture in dry regions for major staple crops. Sci Rep, 2021. 11(1): p. 3344.

20. Czyżewski, B. and M. Guth, Impact of Policy and Factor Intensity on Sustainable Value of European Agriculture: Exploring Trade-Offs of Environmental, Economic and Social Efficiency at the Regional Level. Agriculture, 2021. 11(1).

21. Candemir, A., S. Duvaleix, and L. Latruffe, Agricultural Cooperatives and Farm Sustainability - a Literature Review. Journal of Economic Surveys, 2021. 35(4): p. 1118-1144.

22. Zamarreño-Aramendia, G., E. Cruz-Ruiz, and E. Ruiz-Romero de la Cruz, Sustainable Economy and Development of the Rural Territory: Proposal of Wine Tourism Itineraries in La Axarquía of Malaga (Spain). Economies, 2021. 9(1).

23. Stępień, S., et al., Eco-efficiency of small-scale farming in Poland and its institutional drivers. Journal of Cleaner Production, 2021.279.

24. Srebro, B., et al., Bankruptcy Risk Prediction in Ensuring the Sustainable Operation of Agriculture Companies. Sustainability, 2021. 13(14).

25. Gathala, M.K., et al., Enabling smallholder farmers to sustainably improve their food, energy and water nexus while achieving environmental and economic benefits. Renewable and Sustainable Energy Reviews, 2020. 120.

26. Pang, Y. and X. Wang, Land-Use Efficiency in Shandong (China): Empirical Analysis Based on a Super-SBM Model. Sustainability, 2020. 12(24).

27. Ren, W., et al., Measuring Regional Eco-Efficiency in China (2003-2016): A "Full World" Perspective and Network Data Envelopment Analysis. Int J Environ Res Public Health, 2020. 17(10).

28. Zhong, S. and H. Wang, The effect of total factor productivity of forestry industry on $\mathrm{CO} 2$ emissions: a spatial econometric analysis of China. Sci Rep, 2021. 11(1): p. 14200.

29. Gusmao Caiado, R.G., et al., Towards sustainable development through the perspective of eco-efficiency - A systematic literature review. Journal of Cleaner Production, 2017. 165: p. 890-904.

30. Ber, S.r.A., Malmquist Indices of Productivity Growth during the Deregulation of Norwegian Banking, 1980-89. The Scandinavian Journal of Economics, 1992. 94(Malmquist Indices of Productivity Growth during the Deregulation of Norwegian Banking, 1980-89): p. 211-228.

31. Berg, S.A., Forsund, F. R., \& Jansen, E. S. (1992)., Malmquist Indexes of Productivity Growth during the Deregulation of Norwegian Banking,. Scandinavian Journal of Economics, 1992: p. 1980-89.

32. Iram, S. et al., Congruously designed eco-curative integrated farming model designing and employment for sustainable encompassments. Environmental Science and Pollution Research, 2020. 27(16): p. 19543-19560.

33. Pérez Urdiales, M., A.O. Lansink, and A. Wall, Eco-efficiency Among Dairy Farmers: The Importance of Socio-economic Characteristics and Farmer Attitudes. Environmental and Resource Economics, 2015. 64(4): p. 559-574.

34. Tang, K., M. Wang, and D. Zhou, Abatement potential and cost of agricultural greenhouse gases in Australian dryland farming system. Environmental Science and Pollution Research, 2021.

35. Baum, R. and J. Bieńkowski, Eco-Efficiency in Measuring the Sustainable Production of Agricultural Crops. Sustainability, 2020. 12(4).

36. Biernat, L., et al., Nitrous Oxide Emissions and Methane Uptake from Organic and Conventionally Managed Arable Crop Rotations on Farms in Northwest Germany. Sustainability, 2020. 12(8).

\section{Table 1}


Table 1

Evaluation index and explanation of $\mathrm{AEE}$

\begin{tabular}{|c|c|c|c|}
\hline Index & $\begin{array}{l}\text { Indicator } \\
\text { category }\end{array}$ & $\begin{array}{l}\text { Index } \\
\text { selection }\end{array}$ & Variables and Description \\
\hline \multirow[t]{4}{*}{ Input } & Labor & $\begin{array}{l}\text { Primary } \\
\text { industry } \\
\text { labor force }\end{array}$ & People engaged in agriculture, forestry, animal husbandry, and fishery (Ten thousand people) \\
\hline & Land & $\begin{array}{l}\text { The total } \\
\text { area sown to } \\
\text { crops }\end{array}$ & The total sown area of various crops (Ten thousand mu) \\
\hline & Capital & $\begin{array}{l}\text { Agricultural } \\
\text { intermediate } \\
\text { consumption }\end{array}$ & The value of goods and services consumed in agricultural production and operation (One hundred million yuan) \\
\hline & Technology & $\begin{array}{l}\text { Total power } \\
\text { of } \\
\text { agricultural } \\
\text { machinery }\end{array}$ & Farming, forestry, animal husbandry, fisheries of all kinds of power machinery power sum (Kilowatts) \\
\hline \multirow[t]{5}{*}{ Output } & $\begin{array}{l}\text { Expected } \\
\text { Output }\end{array}$ & $\begin{array}{l}\text { Agricultural } \\
\text { Production }\end{array}$ & $\begin{array}{l}=\sum \text { (Thetotaloutputofanagriculturalproductinthecurrentyear*theproductionpriceofthatagricultural } \\
\text { (One hundred million yuan) }\end{array}$ \\
\hline & \multirow{4}{*}{$\begin{array}{l}\text { Unexpected } \\
\text { output }\end{array}$} & \multirow{3}{*}{$\begin{array}{l}\text { Non-point } \\
\text { source } \\
\text { pollution }\end{array}$} & Fertilizer ×Loss coefficient (Million Tons) \\
\hline & & & Pesticide $\times$ Loss coefficient (Ton) \\
\hline & & & Agricultural Film× Residual rate (Ton) \\
\hline & & $\begin{array}{l}\text { Carbon } \\
\text { Emission }\end{array}$ & Planting $₫$ Breeding $\square$ Fishery comprehensive index(Million Tons) \\
\hline
\end{tabular}

\section{Figures}

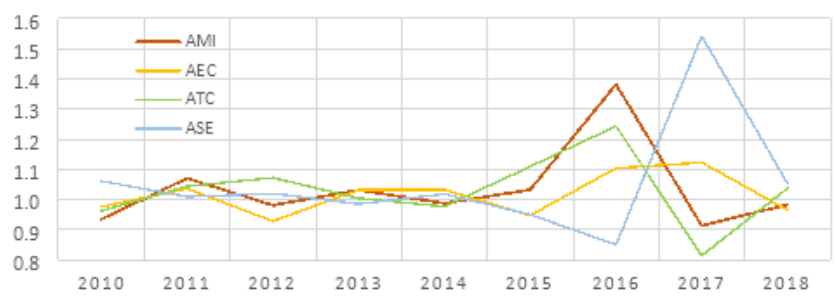

Figure 1

National Average Fluctuation of MI, EC, SE, and TC from 2010 to 2018 (A: Mean Value) 

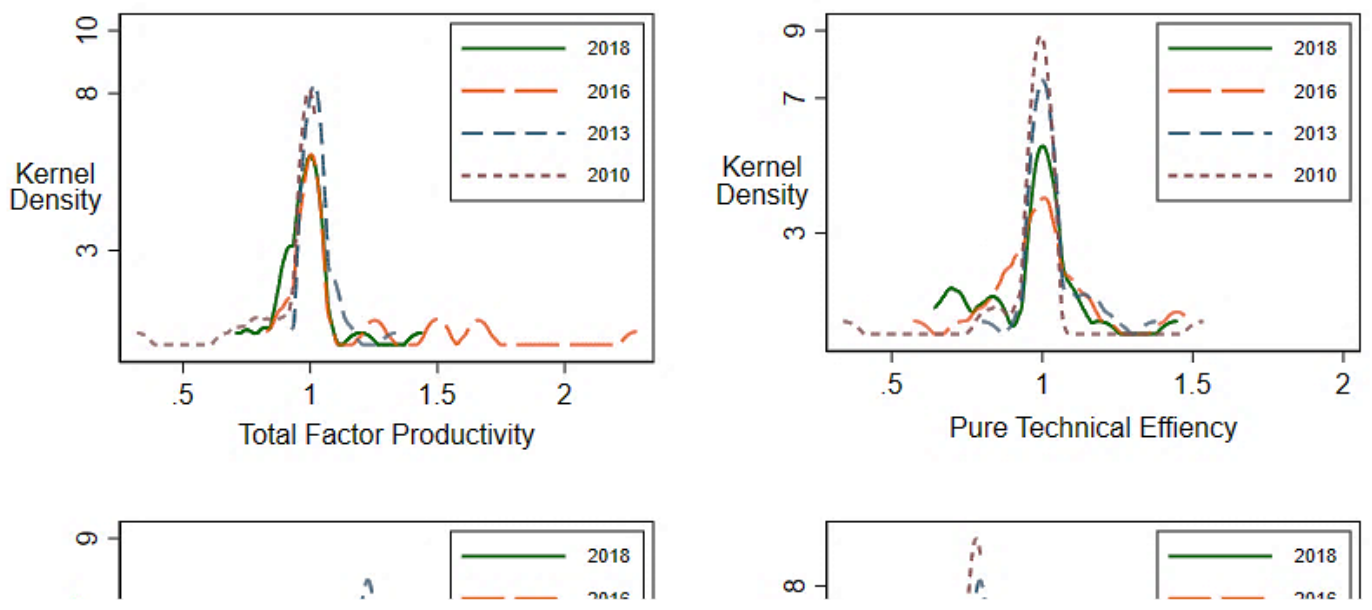

\section{Figure 2}

MI, EC, SE, and TC kernel density distribution in representative years

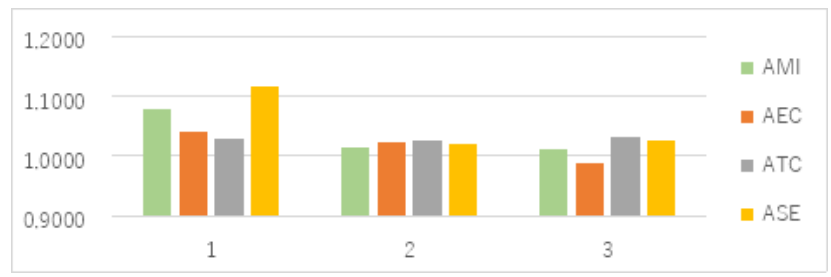

Figure 3

Average distribution of agricultural eco-efficiency (MI, EC, SE, TC) in different regions

Note: 1 is east, 2 is midland, 3 is west. 

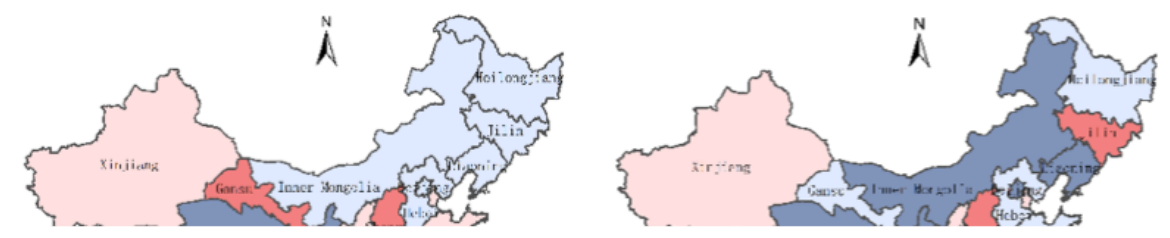

\section{Figure 4}

Spatial geometric mean distribution of AEE in 2018

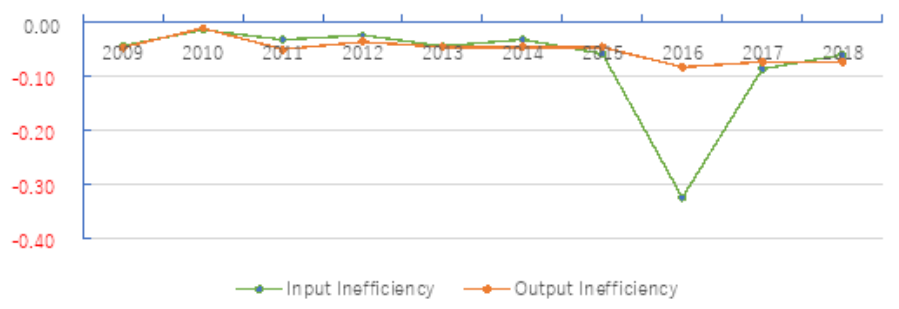

\section{Figure 5}

Overall mean value of input-output inefficiency from 2009 to 2018

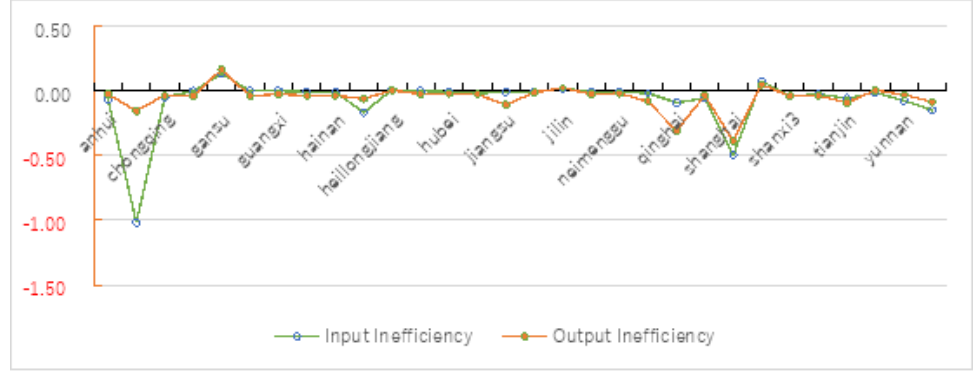

Figure 6

Page 12/13 


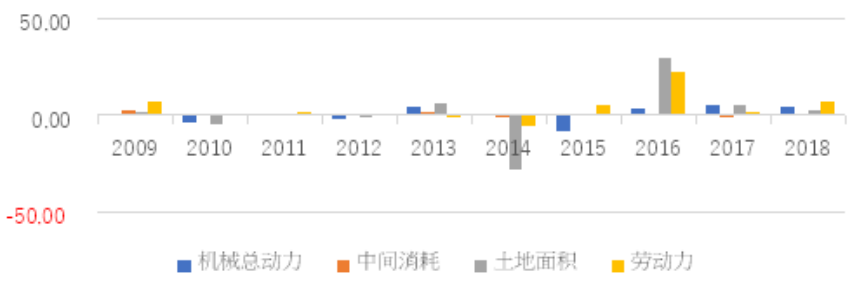

Figure 7

Intensive utilization potential of AEE input factors from 2009 to 2018

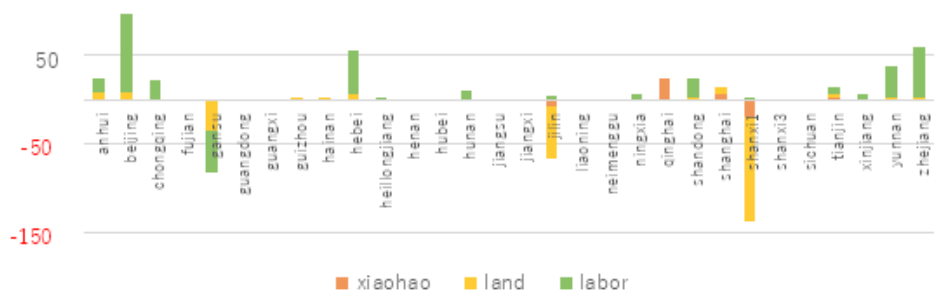

Figure 8

Redundancy means distribution of input factors from 2010 to 2018

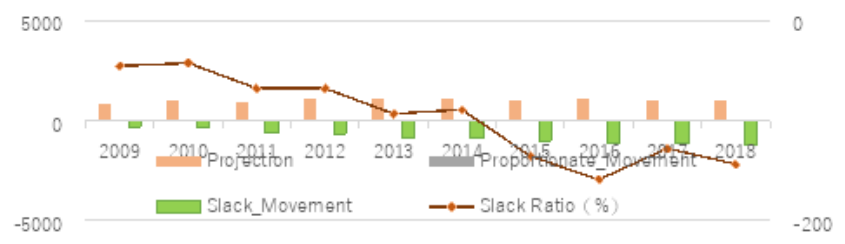

Figure 9

Intensification potential of national average output from 2009 to 2018

\section{Figure 10}

The adjustment potential of the expected mean output of each region

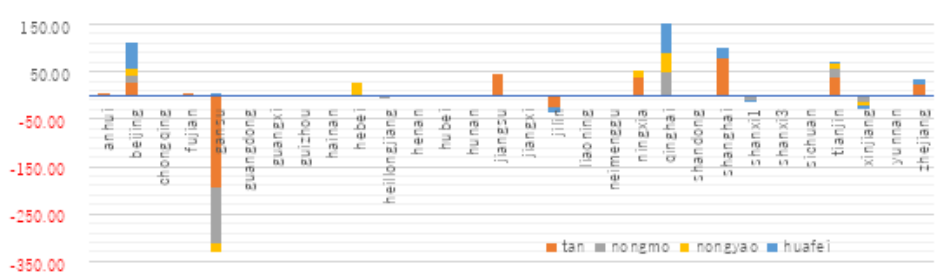

\section{Figure 11}

National emission reduction potential of undesired output from 2009 to 2018

\section{Figure 12}

Box chart of input and output indicators from 2009 to 2018 